\title{
La entrevista de personalidad en las primeras elecciones de la Transición española (1977 y 1979)
}

\author{
David Álvarez BorJaBAD \\ david.alvarez.borjabad@gmail.com \\ Universidad Complutense de Madrid
}

Recibido: 25 de abril de 2014

Aceptado: 13 de octubre de 2014

\begin{abstract}
Resumen
Los elementos personales en general y las entrevistas de personalidad en su particularidad se han erigido como uno de los mejores contenidos para conocer a un personaje, sea cual sea su relevancia, ocupación o perfil profesional. En la Transición española poseyeron una trascendencia capital, por la especial idiosincrasia de un período de numerosos cambios y constantes llamadas electorales. Caracterizado por la entrada en el panorama mediático de un gran número de aspirantes políticos, más los que llevaban mayor tiempo en la escena pública. La estrategia electoral seguida por las diferentes formaciones y la mayor o menor preponderancia de los líderes en los medios de comunicación jugaron un papel muy a tener en cuenta.
\end{abstract}

Palabras clave: entrevista, Transición española, periodismo, política.

\section{The Personality Interview in the First Elections of the Spanish Transition (1977 and 1979)}

\begin{abstract}
Personal features in general, and personality interviews in particular have set themselves up as one of the best contents to get to know a character, whatever his relevance, occupation or professional profile. During the Spanish Transition they possessed a major importance because of the special idiosyncrasy of a period with numerous changes and constant electoral processes. It was characterized by the entry into the media landscape of a large number of aspiring politicians, more those who had already been long time in the public scene. The electoral strategy followed by the different parties and the higher or lower preponderance of the leaders in the media played an important role to take into account.
\end{abstract}

Keywords: Interview, Spanish Transition, Politics, Journalism.

\section{Referencia normalizada}

ÁLVAREZ BORJABAD, David (2015): "La entrevista de personalidad en las primeras elecciones de la Transición española (1977 y 1979)". Estudios sobre el Mensaje Periodístico. Vol. 21, Núm. 1 (enerojunio), págs.: 35-51. Madrid, Servicio de Publicaciones de la Universidad Complutense.

Sumario: 1. Introducción. 2. Metodología. 3. Llegada de la libertad; 3.1. Libertad política; 3.2. Libertad legislativa; 3.3. Libertad periodística. 4. La personalidad como contenido destacado; 4.1. Entrevistas personales; 4.1.1. Tertulias electorales de ABC; 4.1.2. UCD Informa; 4.2. Otros productos periodísticos. 5. Estrategia política. 6. Conclusiones. 7. Referencias bibliográficas. 8. Marcos legales.

\section{Introducción}

Vivimos un período en la historia en la que se encuentran en constante revisión todos aquellos pilares democráticos construidos no hace tanto tiempo. Desde el 20 de noviembre de 1975, con el fallecimiento de Francisco Franco, España comenzó su camino imparable hacia el sistema que vivimos en la actualidad. Con sus aciertos y sus errores, fue virándose de una organización dictatorial a una democrática, sin revolución ni enfrentamiento, integrando y no excluyendo, estableciendo las modificaciones legislativas necesarias para que la voluntad del pueblo español fuera plasmándose y 
asegurándose mediante el ordenamiento legislativo correspondiente en todos los órdenes de la vida, también el periodístico.

Sin duda, un período en la historia en la que salieron a colación un buen número de personajes. Los que tenían su cuota de protagonismo en el Régimen anterior, aquellos que no se habían significado hacia ninguna dirección en los años en los que las libertades no estaban aseguradas, los que habían trabajado en la clandestinidad o los que vivían fuera de nuestras fronteras en contra de su voluntad. Todos demandaban su peso específico trascendente, más aún con la celebración futura de unas elecciones libres, las primeras en más de cuarenta años.

En ese contexto, caracterizado por el reconocimiento expreso de las libertades hasta entonces utópicas en España (política, sindical o de expresión, por citar unos casos), era necesario el conocimiento de todos aquellos candidatos que aspiraban a tener su cuota de protagonismo en el nuevo panorama político. La época denominada como la "sopa de letras", por la cantidad de siglas en liza, en muchas ocasiones con diferencias entre ellas insignificantes, hacía necesario presentar a los candidatos, no sólo en su vertiente política, sino también personal. En esa función los medios de comunicación jugaron un papel trascendental.

Para ello, la entrevista fue un género que gozó de una importancia notoria. Como producto periodístico específico o como base para la realización de otros diferenciados como el reportaje, la entrevista de personalidad en la concepción entendida por el profesor Martínez Albertos (1974: 110-111) u otros estudiosos como Jorge Halperín (1995: 17), o las pequeñas manifestaciones en las charlas genéricas tuvieron su importancia capital para conocer a aquellos hombres y mujeres, bastantes más de los primeros, que entraban en la arena política para la disputa electoral en 1977 y, posteriormente, también en 1979.

Cada una de las principales formaciones políticas, entendidas por ellas a la Unión de Centro Democrático (UCD), al Partido Socialista Obrero Español (PSOE), al Partido Comunista de España (PCE) y a Alianza Popular (AP), luego Coalición Democrática $(\mathrm{CD})$, siguió una estrategia diferenciada. Una planificación que redundaba directamente en los personajes que aparecían en los medios de comunicación, por ende también en los que mostraban su manera de ser, su trayectoria vital, formación académica o gustos y aficiones.

Por tanto, estudiar las entrevistas de personalidad en las dos primeras elecciones de la Transición española, 15 de junio de 1977 y 1 de marzo de 1979, permite conocer a la nueva clase política española del momento, o la no tan nueva, y percibir la incidencia que dichos contenidos tuvieron en la consecución de unos resultados caracterizados por la victoria de las tendencias moderadas frente a los extremos ideológicos. Descubrir a través de dos periódicos diarios (ABC y El País) y dos revistas semanales (Cambio 16 y Triunfo) una labor esencial ante el nuevo proceso democrático emprendido por el país, como era la explicación a la ciudadanía de los entresijos de un sistema arraigado en multitud de estados del entorno, pero no todavía en el nuestro con la fortaleza que le da las raíces vetustas que han sufrido multitud de vicisitudes por el paso del tiempo, es un ejercicio muy enriquecedor de los primeros pasos españoles en ese sentido. 
Coinciden pues, en el mismo tiempo, el desarrollo histórico que permite el cambio de una dictadura a una democracia, la adaptación legislativa en materia periodística para garantizar la libertad de expresión y el derecho a la información, la coexistencia de distintas cabeceras con historias particulares muy diferenciadas, dotándole de diferentes visiones y desiguales productos periodísticos, y la escenificación de las primeras manifestaciones evidentes de la comunicación política en el juego entre los diversos actores participantes. Todo ello fue el caldo de cultivo perfecto para la proliferación de las entrevistas en su generalidad y de los contenidos personales en su particularidad, jugando todo ello un papel trascendental en la presentación y conocimiento de unos candidatos políticos que se iban a convertir desde ese año 1977 en habituales en los hogares españoles. Su presencia en los diferentes medios de comunicación iba a ser constante y el grado de conocimiento para con ellos también, justificado en parte por esos elementos inherentes a su propio ser que aparecieron en la primera campaña electoral, siguiendo la misma tónica en la segunda llamada a las urnas.

\section{Metodología}

El planteamiento ha pretendido buscar la perfecta conjunción entre la entrevista de personalidad, o los rasgos de ésta en las charlas u otros artículos dignos de mención, con la presencia de un período histórico que requería de ellas, al menos en la teoría, de una manera clara. La Transición española fue la época delimitada por las razones expuestas anteriormente, basadas en la implantación de un nuevo sistema político y en la confrontación de gran cantidad de partidos, nuevos o viejos, y de dirigentes políticos de procedencia variada. Y los comicios del 15 de junio de 1977 y del 1 de marzo de 1979 constituyen los momentos en los que dichos elementos gozaron de mayor preponderancia en el menor tiempo.

Para ello, y para poder establecer unas conclusiones lo suficientemente fundamentadas, se antojaba necesaria la selección de un número de publicaciones suficientes y representativas del panorama mediático de aquellos años finales de la década de los setenta. Los periódicos (en este caso el tradicional $A B C$ y el renovador El País) poseían una importancia capital como el principal medio de comunicación, junto con la televisión, y las revistas (la más importante del período, Cambio 16, y la singular Triunfo) eran su complemento ideal, con una trascendencia todavía importante a pesar de la pérdida de importancia en detrimento de los primeros.

La metodología empleada ha consistido en la recapitulación de todos los contenidos hemerográficos relacionados con la contienda en ambas campañas electorales y aparecidos en las cuatro cabeceras. Con ellos, además de la lógica contextualización histórica y temática, se ha podido establecer la preponderancia de los contenidos personales, las diferentes morfologías informativas llevadas a cabo por cada una de las cuatro cabeceras y la influencia que tuvieron en el resultado final de los comicios.

Con toda esa información se podrán atender a los interrogantes que irremediablemente surgen con la presente investigación. ¿Cuáles son los candidatos protagonistas de los productos informativos y qué formaciones son las más proclives al interés de los medios de comunicación?, teniendo en cuenta que en un área como la política la posi- 
bilidad de encontrar textos puros de personalidad se antoja harto complicado, además de las diferencias lógicas entre cabeceras y proyectos muy diversos en origen y desarrollo.

Junto a todas estas cuestiones y a las diferencias periodísticas que pueden establecerse con su mera introducción en la lectura de los cuatro rotativos, hay que tener en consideración otra serie de interrogantes que surgen al profundizar en la materia. El primero y más importante es conocer si la mayor o menor presencia de esos contenidos afectó directamente a los resultados electorales. Y el segundo consiste en verificar si las formaciones políticas vieron la necesidad, en las dos campañas electorales, de elaborar ellos mismos esos textos referidos a la biografía y manera de ser de los candidatos políticos. Centrado, claro está, en los productos escritos en las cuatro publicaciones seleccionadas y siempre en la campaña electoral, siendo los propios partidos, a través de la fórmula que estipulasen, los encargados de materializarla y depositarla en los citados medios de comunicación.

\section{Llegada de la libertad}

\subsection{Libertad política}

Si el 20 de noviembre de 1975 es considerado como el final de una época, cuarenta años de una dictadura tremendamente represora, el 3 de julio de 1976 debe ser tildado como el punto de inflexión para la implantación de la libertad. A partir de ese día comenzaron a acelerarse los necesarios avances a favor del establecimiento de un sistema democrático. Organización del estado que traería consigo aparejada, irremediablemente, la libertad política, sindical o de expresión, que comenzaban a verse en un horizonte no demasiado lejano, aunque la sociedad no fuera consciente de todo ello.

En apenas 11 meses se debatió y elaboró la Ley para la Reforma Política, ordenamiento que permitió que las Cortes Franquistas se hicieran el "harakiri", término empleado por Pilar Urbano; se legalizó el Partido Comunista el denominado "Sábado Santo Rojo", lo que daba pie a la celebración de unos comicios con la participación de todas las sensibilidades políticas, incluso las perseguidas no hacía tanto tiempo; y se celebraron los primeros comicios libres en más de cuarenta años, dando pie a un Parlamento con dos partidos predominantes, UCD y PSOE, y dos con un papel secundario en escaños, no así en peso específico en la vida parlamentaria, AP y PCE.

En esa precisa campaña electoral tuvo lugar, por fin, el juego político en su máximo esplendor. La disputa dialéctica de las diversas tendencias políticas, con los mítines en su fase prehistórica, pero mucho más real que las que se viven hoy en día. La continua emisión de los mensajes electorales, con su componente político, programático y también personal (Canel, 2006:45-51). Los candidatos principales copaban gran parte del espacio en los medios de comunicación, como así lo atestigua la constante aparición de Adolfo Suárez, Felipe González, Manuel Fraga o Santiago Carrillo, aunque éste compartiera protagonismo en la primera llamada a las urnas con Dolores Ibárruri y Rafael Alberti, una mirada al pasado en un tiempo que reclamaba transitar hacia futuro.

Hasta las segundas elecciones no discurrieron ni veintidós meses, pero en ese tiempo la gran preocupación de la clase política, como así lo evidenciaban las temáticas abordadas en la campaña electoral del 15-J y su plasmación en los medios de comunicación, pasaban por la elaboración de una Constitución y la resolución de una 
crisis económica profunda, con el paro, la inflación o la necesidad de una reforma fiscal en el foco de las medidas a adoptar. Para el primer asunto, la Carta Magna fue elaborándose con la colaboración y trabajo de una gran parte del arco parlamentario y para el segundo "Los Pactos de la Moncloa" fueron la mejor evidencia del clima de consenso y acuerdo que todavía se respiraba en la clase política española.

Con la aprobación por referéndum de la Constitución, se había dotado del marco legislativo supremo al sistema político español. El amplio reconocimiento de derechos era la prueba palpable de ello y daba pie al juego político en su máxima expresión, dejando atrás el período de grandes alianzas y comenzando la disputa en toda su magnitud. La construcción de un estado que reconociera los derechos fundamentales había concluido al menos en su parte más trascendental.

Los segundos comicios fueron el inicio de la democracia normalizada, de la proliferación de mensajes políticos y también personales, y de la preocupación en los asuntos del día a día, a excepción de la definición del mapa autonómico. La inseguridad en las calles, la crisis económica, la integración en la OTAN y en la CEE, y la divulgación de asuntos sociales, como el aborto y el divorcio, que estaban de rabiosa actualidad y evidenciaban también aspectos inherentes a la persona con su sola manifestación de pareceres al respecto, copaban no poco espacio en los medios.

En candidatos, volvía a ponerse de manifiesto la preponderancia absoluta del líder sobre la segunda línea de los diversos partidos. Sólo interesaba el cabeza de cartel y las cuatro principales formaciones nacionales siguieron esa tendencia a pies juntillas, incluso el PCE, que obvió la estrategia seguida dos años antes de dar especial trascendencia a los vetustos líderes provenientes del exilio y dio un paso adelante, con Carrillo como principal representante, y se abrió a las nuevas generaciones de líderes que habían realizado su lucha contra la Dictadura dentro de las fronteras españolas.

\subsection{Libertad legislativa}

Una de las principales manifestaciones de la vida en libertad son los medios de comunicación. Cuando éstos ejercen su labor sin injerencias, la decisión de qué se publica, a qué se le concede más o menos importancia y la jerarquización de las informaciones corren a cargo exclusivamente de la dirección del mismo. Es decir, lo que hoy en día está elevado a la categoría de normal, haciendo mío el discurso de Adolfo Suárez en 1976, en aquel tiempo era prácticamente utópico el poder materializarlo.

El sistema legislativo en materia de prensa estaba fundamentado en la Ley de Prensa e Imprenta del año 1966. Esto suponía, ateniéndonos al artículo segundo del presente ordenamiento, que "la libertad de expresión y el derecho a la difusión de informaciones, reconocidas en el artículo primero, no tendrán más limitaciones que las impuestas por las leyes. Son limitaciones: el respeto a la verdad y a la moral; el acatamiento a la Ley de Principios del Movimiento Nacional y demás Leyes Fundamentales; las exigencias de la defensa Nacional, de la seguridad del Estado y del mantenimiento del orden público interior y la paz exterior; el debido respeto a las Instituciones y a las personas en la crítica de la acción política y administrativa; la independencia de los Tribunales, y la salvaguardia de la intimidad y del honor personal y familiar". 
Esto era, en resumen y como era norma y costumbre en la época dictatorial, un enunciado abierto, que permitía su mayor o menor rigidez dependiendo del momento (Muñoz 1999). Pero era insuficiente para un estado democrático. Por ello, evidenciando lo que sucedió en gran parte de los órdenes organizativos, se paso de la ley a la ley, estableciendo las modificaciones que eran necesarias para la garantización de los derechos posteriormente reconocidos en la Constitución.

De esta forma, la promulgación del Real Decreto 24/1977 avalaba la libertad de expresión y el derecho a la información, al tiempo que derogaba el artículo segundo de la Ley de 1966 y el 165 bis b del Código Penal, el encargado de sancionar por el incumplimiento del primero (Castro Torres, 2010:252). Así, quedaban garantizados ambos derechos antes de que el artículo 20 de la Carta Magna dejara constancia de ello.

En definitiva, con esa evolución legislativa, todos los medios de comunicación en general, y los cuatro seleccionados en particular, eran libres para publicar lo que ellos consideraran oportuno, con la línea editorial elegida por cada cabecera. Eso fue también motivo más que suficiente para que surgieran un buen número de cabeceras, caso de El País, y las ya existentes se adaptaran al nuevo tiempo, como ocurrió con el diario $A B C$ y la realización de formatos tan novedosos como las Tertulias Electorales.

\subsection{Libertad periodística}

De gran vinculación con el epígrafe anterior, la libertad trajo consigo aparejada la diversificación del panorama periodístico escrito en nuestro país y el surgimiento de un buen número de rotativos que evidenciaban el nuevo tiempo. La idea de modernidad, adaptación al nuevo contexto político y social, y la apertura de miras al exterior, caso de Europa, eran la nota predominante de un buen número de publicaciones que aparecieron en ese tiempo en nuestro país. El caso más palpable y exitoso fue sin duda El País, que rápidamente se aupó al primer puesto por número de lectores (Sueiro Seoane 2009: 153).

El binomio periódicos-revistas permaneció vigente en la prensa escrita, aunque con la novedad que suponía el aumento del peso específico de los primeros con relación a los segundos. Mientras en el período franquista las mayores demandas de libertad se pronunciaban en las publicaciones semanales, que arriesgaban, y mucho, e iban por delante de la clase política anticuada, Cambio 16 y Triunfo son una buena muestra junto con Cuadernos para el Diálogo; en el nuevo tiempo los periódicos ganaron adeptos. La ciudadanía encontraba diariamente lo que antes existía semanalmente y las reivindicaciones democráticas fueron costumbre en un buen número de cabeceras diarias, por lo que el consumo de los semanarios bajó ostensiblemente. De los 755.000 ejemplares difundidos en 1976 se pasó a sólo 287.000 en 1978, lo que demuestra lo señalado anteriormente (Díaz Dorronsoro, 2012: 253).

Se produjo una coexistencia entre las cabeceras tradicionales, con un gran historial a sus espaldas y que debieron adaptarse a las nuevas peculiaridades del momento, caso de $A B C$ (Olmos, 2002: 529); con los nuevos productos de la época, en los que ya figuraba en su línea editorial la defensa de la democracia, su tendencia europeísta y su modernidad, El País (Sueiro Seoane 2009: 154). En las revistas, Cambio 16 seguía 
erigiéndose como el producto con más respaldo y más innovador del momento, a pesar de su pérdida constante de lectores (Díaz Dorronsoro, 2012: 317); mientras Triunfo era la perfecta muestra de una publicación vetusta, con textos mucho más densos y analíticos, lo que aceleró su desaparición por no saber adaptarse a los requerimientos de la sociedad en aquellos años setenta (Alted y Aubert, 1995: 53).

\section{La personalidad como contenido destacado 4.1. Entrevistas personales}

Tabla 1: cuantificación del número de entrevistas por publicaciones (a excepción de las Tertulias electorales), perfil de los protagonistas de los mismos y contenidos personales existentes en ellas. Elaboración propia con los datos de la investigación.

\begin{tabular}{|c|c|c|c|c|}
\hline & Periódico & Entrevistas & Personajes & Contenidos personales \\
\hline \multirow{4}{*}{$\begin{array}{l}1 \\
9 \\
7 \\
7\end{array}$} & $A B C$ & $\begin{array}{c}12+6 \text { a partidos políticos (UCD, } \\
\text { AP, PSOE, ASD, PSP y PCE) }\end{array}$ & $\begin{array}{c}\text { Políticos destacados (conservadores } \\
\text { mayoritariamente), aspirantes a la presidencia } \\
\text { de las Cortes o senador real, y el presidente del } \\
\text { Gobierno }\end{array}$ & $\begin{array}{l}\text { Biografía, trayectoria profesional, } \\
\text { descripción del emplazamiento y } \\
\text { consideración del aborto }\end{array}$ \\
\hline & El Pais & $\begin{array}{c}5 \text { en la Guia para votar }+1 \text { en el } \\
\text { Especial Elecciones }+1\end{array}$ & $\begin{array}{l}\text { Cabezas de cartel (PSOE, PCE, AP, PSP y } \\
\text { FDC), político reputado (Areilza) y político } \\
\text { italiano (Francesco Cossiga) }\end{array}$ & Biografia \\
\hline & Cambio 16 & 4 & $\begin{array}{c}\text { Cabezas de cartel (González, Carrillo y Fraga) } \\
\text { y político de formación secundaria (Mariano } \\
\text { Sánchez Covisa) }\end{array}$ & $\begin{array}{c}\text { Biografia, descripción del lugar y aspectos } \\
\text { concretos }\end{array}$ \\
\hline & Triunfo & 5 & $\begin{array}{c}\text { Cabeza de cartel (González), políticos } \\
\text { destacados (José Aumente y Enrique Fuentes } \\
\text { Quintana) y líder internacional (Alain Krivine) }\end{array}$ & Biografia \\
\hline \multirow{4}{*}{$\begin{array}{l}1 \\
9 \\
7 \\
9\end{array}$} & $A B C$ & $\begin{array}{c}\text { 6+ } 4 \text { a partidos políticos (PCE, } \\
\text { DCD, CD y UCD) }\end{array}$ & $\begin{array}{c}\text { Ministro de Gobernación y candidatos } \\
\text { conservadores (Fraga, Areilza y Arias Salgado) }\end{array}$ & $\begin{array}{c}\text { Biografia, referencias físicas, aborto y } \\
\text { divorcio }\end{array}$ \\
\hline & El Pais & 1 & Ramón País (CD) & Biografía \\
\hline & Cambio 16 & 3 & $\begin{array}{c}\text { Cabeza de cartel (Fraga), político descatado } \\
\text { (Alfonso Guerra) y político de formación } \\
\text { secundaria (duque de Tovar) }\end{array}$ & $\begin{array}{c}\text { Biografía, descripción del lugar, aborto y } \\
\text { divorcio }\end{array}$ \\
\hline & Triunfo & 4 & $\begin{array}{c}\text { Líderes políticos regionales (Josep Benet, } \\
\text { Andreu Abelló, Alejandro Rojas Marcos y } \\
\text { Eladio García Castro) }\end{array}$ & Retazos minúsculos \\
\hline
\end{tabular}

Ese binomio claro entre los periódicos y las revistas, entre la inmediatez y el análisis, entre las obligaciones que entraña el aquí y ahora, con las centradas en ofrecer un producto diferenciado y mucho más analítico que los primeros, queda de manifiesto en la proliferación de unos géneros en detrimento de otros, con la entrevista como objeto central del análisis. No sólo se debe hablar de la variación entre un tipo de publicaciones y otras, sino que entre los dos rotativos de similar idiosincrasia, pero diferente trayectoria, línea editorial y formato, se encuentran un buen número de ellas que puede explicar las enormes diferenciaciones numéricas existentes entre los guarismos del $A B C$ y El País, no así en las revistas que poseyeron cifras bastante parejas.

En lo que a la trascendencia del género de la pregunta y respuesta hace referencia, aunque sus manifestaciones puedan llevarse a término en multitud de morfologías que lo convierten en un producto con multitud de manifestaciones, hubo una cabecera predominante, sin ningún atisbo de duda. $A B C$ contuvo en sus páginas la mayor cantidad de representaciones del género tanto en 1977 como 1979, sin contabilizar las charlas 
existentes en las Tertulias electorales, de las que posteriormente nos haremos eco y que darán unos dígitos notables. Raro era el ejemplar que, de una u otra manera, no contuviera ninguna y así se puso de manifiesto, con dieciocho y diez casos.

Su rival en los quioscos estableció una política informativa diferenciada. Ciñéndose única y exclusivamente al ejemplar normal del diario, sólo se debe hablar de una representación en cada llamada electoral. En 1977 el protagonista fue Francesco Cossiga, ministro del Interior italiano, y en 1979 Ramón País, en un espacio anunciador de CD a imagen y semejanza de los UCD informa, contenidos realizados por la coalición centrista y sobre los que posteriormente abordaremos sus especificidades principales. Fuera de las páginas normales, en los comicios del 15-J, se elaboraron dos productos complementarios que sí concedieron una relevancia porcentual mucho mayor a las entrevistas. Principalmente en la Guía para votar, por la que discurrieron los principales espadas de las formaciones políticas más importantes del momento, a excepción de Adolfo Suárez, que como presidente del Gobierno efectuó una campaña diferenciada, no exenta de polémica.

Las publicaciones semanales, por su parte, no poseían unas diferencias entre ellas muy significativas. Las cuatro y tres presencias en Cambio 16, y las cinco y cuatro de Triunfo, en 1977 y 1979 respectivamente, permite asegurar que constituían un género empleado con cierta regularidad. No obstante, el peso específico notable en dichas cabeceras la poseían otros tipos de productos periodísticos que, en no pocas ocasiones, tenían a la praxis propia de la entrevista como acción esencial para el éxito de unos textos con presencia notable de contenidos personales.

Los protagonistas de todas las charlas publicadas en ambas campañas electorales procedían de motivaciones muy diferentes, es decir, de consideraciones particulares que les llevaron a realizar dicha entrevista. Los diversos candidatos políticos participantes en la contienda, con especial trascendencia para aquellos cabezas de cartel de las principales siglas (Adolfo Suárez, Felipe González, Santiago Carrillo y Manuel Fraga), sin desdeñar tampoco al resto de aspirantes a pesar de su influencia en número de votos mucho menor; los dirigentes políticos protagonistas de acontecimientos en aquel tiempo (Antonio Hernández Gil, al ser abordado en junio de 1977 como presidente de las Cortes, o Rodolfo Martín Villa, en calidad de ministro del Interior, son dos de los ejemplos), determinados profesionales que afrontaban asuntos específicos de una temática de la que eran expertos (Enrique Fuentes Quintana en la primera campaña y en las páginas de Triunfo abordó la coyuntura económica) o representantes políticos de cierta trascendencia, como el ya citado Francesco Cossiga, fueron requeridos para la realización del género de la pregunta y respuesta en las cuatro cabeceras.

Dentro de la especificación política que indudablemente tiene la proliferación de charlas y contenidos personales con los resultados electorales, lo cierto es que los primeros espadas copaban los espacios de las publicaciones menos apegadas a la actualidad, las revistas, y su profundidad era mucho mayor, en lo que a los contenidos inherentes a la manera de ser hace referencia. La prensa diaria, por la lógica vinculación con el aquí y ahora, no daba pie a mucho más que charlas en las que se abordara un aspecto concreto de la campaña electoral. Lo materializaban con cuestionarios muy apegados con la actualidad del momento, en la que la proliferación de elementos per- 
sonales no era el contenido principal del mismo y los líderes mucho más variopintos que la búsqueda del primer espada.

En líneas generales debe hablarse de una existencia constante, no continua, de los elementos personales, con una proliferación más numerosa en las revistas que en las publicaciones diarias por el motivo antes expuesto. En el menor número de los casos, la introducción de dichos contenidos venía precedido de una pregunta personal y en el mayor en los primeros párrafos o entradillas, textos con tipografía diferenciada al resto del cuerpo del producto periodístico. La especificación del lugar, del emplazamiento en el que se desarrolló el encuentro o aspectos curiosos que se desarrollan en el lógico devenir de los acontecimientos, dan lugar a la presencia de elementos propios del cuestionado, que permiten adentrarse en su personalidad. También la lógica especificación de la biografía del cuestionado, que adjuntamos junto con una muestra del caso anterior referida al ministro Rodolfo Martín Villa en 1979, expuesta primero:

- "Le han arreglado las gafas. Ya no se le caen ni necesita recolocarlas con ese tic nervioso que inquietaba a medio país y erizaba al otro medio. Ahí está, en su madriguera; en su pequeño despacho, en el palacete sobredorado y cursi, detrás de una mesa enorme que le cobija y protege. Es el ministro-angustia, el ministro-zozobra, el ministro-sobresalto. Suave, casi delicados, son sus modales, contenido el gesto, la voz baja y grave, los ojos de carbón leonés, duros y negros, de metralla." (Redacción. "Sólo determinadas funciones de orden público serán encomendadas a la policía autónoma". ABC, 23 de febrero de 1979, p. 6)

- "A las siete de la tarde, como había anunciado Fraga, se sentó en el sillón negro de piel de su despacho aliancista, giró las clavijas de todos los teléfonos de sobremesa y se dispuso a hablar con los periodistas en línea personal directa. Muy buenas tardes, estoy a su entera disposición; usted dirá. Es el Fraga de las graves circunstancias, fortiter in re, suaviter in modo, encajando con bizarría el descalabro." (Urbano, P. "Fraga: acepto los resultados, pero..." $A B C, 3$ de marzo de 1979, p. 19)

\subsubsection{Tertulias electorales de $A B C$}

Tabla 2: cuantificación del número de entrevistas contenidas en las Tertulias electorales de $A B C$ en 1977 y 1979, así como la división porcentual de las mismas en función del perfil profesional. Elaboración propia con los datos de la investigación.

\begin{tabular}{|c|c|c|c|c|c|c|}
\cline { 2 - 7 } \multicolumn{1}{c|}{} & Total entrevistas & Políticos & Periodistas & Artistas & Otros & Contenidos personales \\
\hline 1977 & 327 & $37 \%$ & $15 \%$ & $11 \%$ & $37 \%$ & Definición personal y política \\
\hline 1979 & 215 & $41 \%$ & $6 \%$ & $12 \%$ & $41 \%$ & $\begin{array}{c}\text { Aborto, divorcio y antecedentes } \\
\text { familiares }\end{array}$ \\
\hline
\end{tabular}

Género estrella del diario monárquico en las dos campañas electorales, debe ser tildado como el más destacado por varias consideraciones. "Recogió el guante", si se permite la expresión, de los anhelos de una sociedad española que demandaba la confrontación de pareceres entre las numerosas opciones políticas existentes; y cuantitativamente constituyó la sección de prensa escrita que le ha dado una mayor importancia al género de la entrevista en toda la investigación. Las 327 representaciones del género en 1977 y las 215 en 1979 evidencian este hecho, así como otra serie de pretextos relativos a la extensión de las mismas, que no podía exceder las tres o cuatro cuestiones en el mejor de los casos. 
Referirse en la actualidad a las tertulias electorales en toda su amplitud es hacerlo a un género, siempre hablando en el contexto de la dura pugna de la campaña electoral, que ha ido ganando trascendencia con el paso de las llamadas electorales. En aquel tiempo, según la periodista Pilar Urbano, una de los muchos profesionales que desempeñaban su labor en la cabecera fundada por Torcuato Luca de Tena y en el producto diferenciador de la cabecera monárquica, "se juntaron varios factores. Había un elemento externo importante e influyente que era El País, la competencia; un instinto periodístico en los jefes de que España cambiaba, entonces había que abrirse; el poco tiempo y mucho protagonismo, por el que no daba tiempo a cada día una entrevista; y la presencia de algo tan novedoso y nuevo que podía ocupar varias páginas, como podía ser el debate entre ellos, convirtiéndose en una especie de circo, en la arena, la contienda".

Por perfiles profesionales se evidencia como, por otra parte es lógico dada la cercanía de la llamada electoral, el número de políticos siempre era el más demandado, con un $37 \%$ en la primera convocatoria y un $41 \%$ en la segunda. Eran mayoritariamente ellos los que acudían invitados para exponer su línea personal y de partido en aquellos asuntos principales de preocupación para la ciudadanía española, dando construcción a unas tertulias muy participativas y abiertas a la práctica totalidad del futuro arco parlamentario. Sólo la no presencia del PCE en 1977, por motivos meramente ideológicos, fue la única ausencia trascendente. El resto tuvieron representación mayor o menor, hasta aquellas siglas tan minúsculas que no lo hicieron en ninguna otra cabecera.

Debido a la morfología de las entrevistas, realmente breves, la cabida de elementos personales era ínfima. Los lectores se encontraban ante contenidos meramente informativos, relativo a las líneas programáticas de las diversas formaciones o aspectos abordados en la tertulia, cada día centrada en una temática global. Extrayendo los únicos componentes verdaderos de entrevistas de personalidad, ya sea porque la pregunta también lo era o porque la respuesta derivaba hacia contenidos de la propia persona, de su interior o pensamientos, se concluye que los elementos meramente de esta tipología eran escasos. Se centraban, principalmente, en la definición de la tipología de ser del entrevistado a cargo de sí mismo, su concepción política, sus opiniones o preferencias a la hora de votar, la conjunción de su vida profesional con la política o la especificación de alguna opinión que con su mera afirmación se expone también rasgos propios del personaje, caso del parecer con respecto al aborto o al divorcio:

- "Soy apolítico. Lo que me gusta es trabajar y que me dejen trabajar". (En VV.AA. José Márquez: Soy apolítico. ABC, 29 de mayo de 1977, p.13)

- "Mis apellidos condicionan la trayectoria de mi vida. Pero no quiero anclarme en ellos. De igual modo que el pueblo español hoy debe asumir su pasado, la guerra, la dictadura, comprenderlo y mirar al futuro, yo quiero que mis apellidos también me hagan mirar el porvenir". (En VV.AA. José Alcalá-Zamora: Mis apellidos condicionan la trayectoria de mi vida. $A B C, 8$ de febrero de 1979, pp. 41-42)

- "Precisamente por eso, porque estoy convencido de que el derecho a la vida es uno de los derechos radicales del hombre, soy contrario a la pena de muerte y soy contrario al aborto libre. Podrá replicárseme que en el caso de la pena de muerte el que la sufre es por haber cometido algún delito grave, mientras que la criatura concebida y no nacida es to- 
talmente inocente." (En VV.AA. "Joaquín Ruíz-Giménez: Rechazo igualmente aborto, pena de muerte y eutanasia". ABC, 7 de febrero de 1979, p. 46)

\subsubsection{UCD Informa}

Los espacios publicitarios contratados y elaborados por la coalición de centro, e introducidos en los dos periódicos diarios analizados simultáneamente, constituyen las entrevistas de personalidad por antonomasia y la más fiel representación en los dos períodos de estudio. Aquellas que mostraron a un total de trece candidatos centristas al Congreso y Senado por la circunscripción de Madrid de la llamada segunda línea (Leopoldo Calvo-Sotelo, Miguel Herrero de Miñón o Carmela García Moreno es una buena prueba de ello), que salvo dos excepciones no estaban presentadas en el tradicional formato de pregunta-respuesta, sino en forma de relato, y que permitían conocer aspectos tan esenciales para ubicar la trayectoria de la persona como su biografía, en lo que a la infancia, familia y formación académica hace referencia, junto con sus aficiones:

- "Mucho ha llovido desde que el niño Armando Benito, hijo de un ferroviario de UGT, paseaba bajo la lluvia por el puntal de Fuenterrabía, contento con su travesura de sentirse calado hasta los huesos. La huida por la frontera de Irún -donde nació hace cuarenta y siete años menos cuatro días- escapando de las tropas durante la Guerra Civil. La emigración en Francia. Y el miedo de una Barcelona bajo los bombardeos. Recuerdos que marcaron para siempre su memoria infantil.” (Aleixandre Ybargüen, J.J. "Así es y así piensa Armando Benito". $A B C, 13$ de febrero de 1979, p. 48)

- "Joaquín Satrústegui es un trabajador incansable. Nunca ha limitado a ocho horas su jornada laboral. Tiene cuatro hijos, ya independientes. Dos nietos. Ahora vive sólo con su mujer, compañera ideal de su vida, más compenetrado con ella que nunca. Y desde que fue elegido senador abandonó todas sus actividades para dedicar a la política su jornada sin límites." (Aleixandre Ybargüen, J.J. "Así es y así piensa Joaquín Satrústegui”. $A B C, 15$ de febrero de 1979, p. 44)

- "La verdad es que cuando llegó el momento de estudiar en serio -gracias a una beca que le concedieron y dando clases particulares para ayudarse- se licenció en Derecho, se graduó en Periodismo y lleva ya un montón de años de subdirector del diario en el que firma su columna." (Aleixandre Ybargüen, J.J. “Así es y así piensa Luis Apostúa”. $A B C$, 18 de febrero de 1979, p. 42)

- "Nunca puede cerrar su mente con tres llaves a las preocupaciones del despacho, de la cátedra y de la política. Y cuando llega el descanso del verano lo emplea en escribir un libro. Su única válvula de escape es montarse cuando puede en una bicicleta de carreras que tiene siempre a punto y hacerse un buen montón de kilómetros carretera adelante." (Aleixandre Ybargüen, J.J. “Así es y así piensa Óscar Alzaga”. $A B C, 22$ de febrero de 1979, p. 42)

Fueron un total de trece entrevistas en las quince jornadas de duración de los espacios, justo la amplitud de la campaña electoral, y deben ser tildados como los elementos principales de los UCD informa. Las otras dos sirvieron para la introducción de un texto propagandístico que ponía en valor los logros alcanzados en la legislatura constituyente y para la publicación de una carta del presidente Suárez. Pero lo realmente interesante fueron las conversaciones mantenidas por el autor, José Javier Aleixandre Ybargüen, libre para realizar unos textos similares a los que estaba 
acostumbrado a redactar en la revista Actualidad Española, no así en la lista de protagonistas, que le vino dada por la formación centrista.

Daba igual el personaje, el autor adaptaba el texto a las peculiaridades de cada uno de ellos para acabar sabiendo de todos los mismos aspectos antes mencionados, con los rasgos propios del candidato. Su mera comprobación, mediante los ejemplos adjuntados, permite ver las diferencias entre ellos, pero también sus elementos comunes.

\subsection{Otros productos periodísticos}

Tabla 3: cuantificación del número de productos periodísticos con la entrevista como una de las bases principales para su elaboración, perfil de los protagonistas de los mismos y contenidos personales existentes en ellos. Elaboración propia con los datos de la investigación.

\begin{tabular}{|c|c|c|c|c|}
\hline & Periódico & Productos periodísticos & Personajes & Contenidos personales \\
\hline \multirow{4}{*}{$\begin{array}{l}1 \\
9 \\
7 \\
7\end{array}$} & $A B C$ & & & \\
\hline & \multirow[t]{3}{*}{ Cambio 16} & 6 artículos personales & $\begin{array}{c}\text { Cabeza de cartel (Suárez), políticos } \\
\text { destacados (Montseny, Alberti, } \\
\text { Pasionaria, Calvo-Sotelo y Pilar } \\
\text { Primo de Rivera) }\end{array}$ & $\begin{array}{c}\text { Biografia, aficiones, retazos } \\
\text { ideológicos }\end{array}$ \\
\hline & & Sombra a Felipe González & Cabeza de cartel (González) & Biografia \\
\hline & & Comparativa & Cabeza de cartel (Fraga y Carrillo) & Metáforas personales ( $\mathrm{coz}$ y martillo) \\
\hline \multirow[b]{3}{*}{$\begin{array}{l}1 \\
9 \\
7 \\
9\end{array}$} & $A B C$ & & & \\
\hline & El Pais & & & \\
\hline & Cambio 16 & 6 artículos personales & $\begin{array}{c}\text { Cabeza de cartel (Carrillo, Fraga y } \\
\text { Piñar), políticos destacados (Oreja, } \\
\text { Múgica, Garrigues Walker y mujeres } \\
\text { candidatas), exiliado (Carlos Gutiérrez) } \\
\text { y ciudadanos anónimos }\end{array}$ & $\begin{array}{l}\text { Biografia, rasgos personales } \\
\text { diferenciadores y aficiones }\end{array}$ \\
\hline
\end{tabular}

Analizando, como se está haciendo, las entrevistas de personalidad en las dos primeras campañas electorales de la Transición española, se antoja un objetivo de obligado cumplimiento el hecho de examinar aquellos contenidos similares que no aparecieron en la fiel representación del género, sino en otras morfologías diferenciadas. Pueden tildarse como entrevistas, con diferentes manifestaciones, pero para enfatizar las diferencias entre ambos, las denominaremos artículos personales, cuando se refieren a un determinado personaje para resaltar algún acontecimiento noticioso y, junto a ello, adentrarse en su propio ser; genéricos, encargados de repasar la realidad de un espectro más global; sombras, o el seguimiento que se realiza a un determinado candidato durante un tiempo acordado viviendo con él, en primera persona, todas las experiencias y acontecimientos; y las comparativas, en las que se pone en valor los rasgos distintivos de un número de candidatos políticos para que en el contraste queden de manifiesto las peculiaridades propias de cada uno de ellos.

La personalidad tuvo su cabida con mayor notoriedad en este tipo de textos, mucho más trascendentales para el objeto del estudio que las charlas anteriores, a excepción de los espacios publicitarios centristas. Son otra morfología de artículos que se han desarrollado en las publicaciones semanales, merced a esa disparidad existente entre el formato de uno y de otro caso. Sólo el reportaje de la vida del presidente Suárez en 
el Palacio de la Moncloa, al poco de trasladarse y publicado en el dominical de $E l$ País, constituye el único ejemplo de la prensa diaria, aunque en la tipología semanal, por lo que no es tanta la diferencia. Un particular en el que tiene como principal elemento la descripción de su vida en la esfera familiar, ligeramente diferente a la especificación de la biografía:

- Los menores son los que más han agradecido el cambio... por el jardín, explica Adolfo Suárez padre. Los otros, no tanto, tenían sus pandillas en San Martín de Porres, y allí se escapan en cuanto puede." (Alonso, J. "Los Suárez, en casa”. El País Semanal, 5 de junio de 1977, p. 19)

El resto, ya sea mediante los artículos personales, las comparativas, los artículos genéricos o las sombras, fueron monopolio de las revistas. En ellas se observa como los protagonistas solían ser con mayor asiduidad los principales cabezas de cartel de las diversas formaciones, a excepción de casos perfectamente justificados y que no deben suponer una singularidad a la tendencia mayoritaria, sino un complemento. Los productos centrados en Rafael Alberti o La Pasionaria, los dos aspirantes por Guipúzcoa, las cinco mujeres candidatas en 1979 o Joaquín Garrigues Walker son un perfecto ejemplo de dichos particulares.

En todos estos productos hubo posibilidad para la presencia de los contenidos personales, de muy diversas morfologías, pero todos con unas peculiaridades propias. La mera presentación del personaje, la especificación de anécdotas vitales que marcaron su trayectoria, las manías o costumbres, las aficiones o su familia fueron los más extendidos cuantitativamente. Diversos todos ellos entre sí, pero personales al fin y al cabo:

- "No soy más que una militante libertaria. Ni líder, ni dirigente, ni jefe, porque en la CNT no ha habido, ni hay, jefes, dirigentes ni líderes, sino hambres y mujeres libres que luchan codo a codo, en igualdad de condiciones y sacrificios, por un ideal emancipador [...] Pese a los setenta y dos años cumplidos, que blanquearon su pelo e inclinaron su figura, Federica Montseny se expresa con la precisión, el vigor y la energía de sus años juveniles". (De Guzmán, E. "Federica Montseny en Madrid". Triunfo, 4 de junio de 1977, p. 11)

- "Su primera visita, en el pasado, no fue tan amable, o tan parlamentaria, como las que ahora van a producirse. En 1962, en efecto, vino por primera vez a la capital de España encadenado a una cuerda de presos, para pasarse ocho años (pasó tres u medio, en efecto) en el penal de Burgos, por ser uno de los creadores de un movimiento de inspiración comunista que usó el slogan Viva Canarias libre. (Calzadilla, J. "Fernando Sagaseta: un nacionalista canario en el Parlamento". Triunfo, 24 de marzo de 1979, p. 22)

- "Como todas las noches desde hace catorce años, Felipe González Márquez, responsable máximo de la organización que se vislumbra como la segunda fuerza electoral de un país hambriento de democracia, ha abierto tranquilamente El Quijote y, con los ojos ya cansados de recorrer caminos, ha comenzado a leer el libro de Miguel de Cervantes Saavedra, por vigésima vez, para recordar los consejos del Caballeros de la Triste Figura a su escudero Sancho Panza, para el buen gobierno de la Península Barataria." (Oneto, J. y Socías, J. "Huracán Felipe". Cambio 16, 12 de junio de 1977, p. 11)

- "Silvia Arburúa de Oreja tiene treinta y cinco años, es rubia, pausada y prudente. Tina Díaz de Múgica, treinta y seis años, es pelirroja, inquieta y contestataria. Las esposas de los candidatos número uno en Guipúzcoa, por UCD y PSOE, ofrecen la perfecta imagen de los partidos de sus maridos. ("Será muy duro". Cambio 16, 4 de febrero de 1979, p. 18) 


\section{Estrategia política}

La táctica seguida por las diversas siglas en liza puede parecer un contenido ajeno al objeto de estudio, pero no debe ser considerado como tal. La proliferación de unos candidatos en detrimento de otros debe ser entendida como un compendio claro de justificantes. Uno procedente de la propia formación en cuestión, que prefieren dar más protagonismo a una serie de aspirantes en detrimento de otros; y otro del medio de comunicación, lo que en función de la estrategia seguida por cada uno de los partidos políticos hace que el atractivo de un personaje en detrimento de otro sea mayor, unido también a una serie de consideraciones personales.

Si una afirmación ha quedado nítida en la comprobación de los elementos personales en la prensa escrita de la época es la proliferación del líder de manera absoluta, salvo pequeños matices, en parte justificado por la inmediatez que requiere el día a día y por las peculiaridades personales de determinados personajes. El artículo referido a cinco mujeres candidatas, en un tiempo en el que la incorporación de las mismas a la vida pública era todavía muy reducida; o el referido a Marcelino Oreja y Enrique Múgica, candidatos en la peligrosa circunscripción de Guipúzcoa, ejemplifican la cuestión.

$\mathrm{UCD}$, PSOE y AP, posteriormente CD, plantearon una estrategia pareja. Las tres dieron un peso sideral a Suárez, González y Fraga, respectivamente, sabedores de que eran ellos, y principalmente ellos, los que arrastrarían para bien o para mal el mayor caudal posible de votos hacia su proyecto. La excepción la encontramos en los mencionados UCD informa, que sirvieron para presentar a la segunda línea de un partido muy heterogéneo o de calmar las ansias de protagonismo de una formación con muchos líderes que ansiaban ocupar la presidencia del Gobierno, aunque siempre se mostraran a la sombra de Suárez. Por parte socialista, el matiz se encuentra en la dura pugna de las tendencias diversas en la llamada a las urnas de 1977, lo que provocó que González y Tierno Galván compartieran protagonismo en ellas, aunque el líder sevillano siempre fuera el principal foco de atención del partido que, a la postre, se alzaría con el respaldo mayoritario del voto progresista moderado, merced a la idea de modernidad que intentó transmitir a la ciudadanía española.

En el caso del PCE se produjo una circunstancia diferente, completamente anquilosados en el pasado. Las peculiaridades comunistas, con un gran número de miembros de la formación que volvieron del exilio en las fechas inmediatas al 15-J, deparó una campaña electoral en la que el protagonismo fue compartido entre el propio Carrillo, La Pasionaria y Rafael Alberti. Ese planteamiento pudo explicar los malos guarismos de las primeras elecciones, al tratarse de un tiempo que requería de una mirada a lo que estaba por venir, no a lo ya transcurrido. El cambio en los segundos comicios, en los que Carrillo emergió como el líder preponderante, al igual que sus contrincantes, se vio reflejado en un aumento de votos, no espectacular pero si reseñable.

\section{Conclusiones}

En un estudio electoral como el presente, en el que se han analizado la presencia de contenidos personales en las entrevistas, esa doble perspectiva es la que debe tenerse en consideración a la hora de plasmar las conclusiones. Por un lado, conviene asegu- 
rar que la presencia de la entrevista en la prensa española debe ser tildada como constante, con notables variaciones dependiendo de la cabecera ( $A B C$ la introdujo en mayor magnitud que El País, que tenía unas apariciones ínfimas) y que su utilización en la realización de otros productos diversos ha sido notable, como lo atestiguan los contenidos presentes en las revistas semanales.

Pero es la imagen de los candidatos la que se ve más o menos reforzada con la introducción de ese tipo de contenidos. La manifestación de la manera de ser, trayectoria vital o aficiones de los diversos aspirantes han ejercido unas labores claras: presentarlos como ciudadanos normales, nada alejados de la realidad social española, con problemáticas parejas al pueblo, mostrar su grado de preparación de cara al puesto que aspiraban a ocupar y establecer unos lazos de empatía con los futuros votantes, redundando positivamente en lo que al número de sufragios hace referencia.

La cuantificación de la importancia que tuvo la trasmisión de la personalidad de los candidatos se antoja un objetivo utópico. Es imposible estipular en cifras la importancia de ello, lo que si pueden establecerse son tendencias al respecto. Nadie duda que la buena imagen que transmitía el presidente Suárez por una gran cantidad de motivos, como fue su labor al frente del Ejecutivo los años anteriores o su dimensión personal, redundara positivamente a favor de su partido político. De la misma manera que debe considerarse que la estrategia materializada por la formación comunista en 1977, con una clara conexión al pasado, fue razón más que suficiente para que el número de votos alcanzados fuera muy inferior al que sus propias estimaciones habían contabilizado en las fechas anteriores.

En la actualidad la realidad que se vive en la comunicación política está mucho más evolucionada que en aquellos no tan lejanos años setenta, la prehistoria de dicha disciplina en España. Hoy el candidato es archiconocido desde los primeros instantes de su labor pública, numerosas vías hay para ello. En aquel tiempo, en parte por la premura existente entre las reformas emprendidas y los comicios, también por la falta de tantos soportes como los que existen en la actualidad y la gran cantidad de políticos que había que presentar en el menor tiempo posible, no había tal.

La disciplina comunicativa siempre ha jugado un papel trascendental. Nadie duda que la campaña realizada por el presidente norteamericano Barack Obama, por citar un caso actual, tuviera como uno de sus pilares fundamentales el conocimiento de su propia personalidad y las vicisitudes de su vida. Remontándonos a los primeros albores democráticos recientes, el hecho cierto es que esa dimensión también fue fundamental, acompañado de las líneas programáticas de la formación.

Durante los primeros años posfranquistas emergieron un buen número de líderes políticos de muy diversa procedencia: las estructuras dictatoriales, la sociedad no perseguida, los repetidamente represaliados o aquellos procedentes del exilio. Todos ellos entraron en la arena política para la búsqueda del mayor apoyo posible y para lograr una representación que les permitiera convertirse en fundamentales en el nuevo tiempo.

Y finalmente el periodismo, como se ha podido comprobar en la presente investigación, tuvo su papel trascendental. Su labor pedagógica, explicando los pormenores del nuevo sistema y todas aquellas dudas que pudieran surgir en la sociedad española ante un modo de comportamiento que no conocían; la informativa, exponiendo todos 
aquellos acontecimientos que se estaban desarrollando a lo largo y ancho de la geografía española, con multitud de mítines y actos varios de campaña en los que el entusiasmo de la ciudadanía en la primera llamada, la moderación ya en la segunda, fue la nota predominante; y la presentación que hacían de los candidatos, en un tiempo que exigía de dicha tarea para que el voto de cada uno de los habitantes del país contara con el mayor conocimiento político, programático y personal, fueron las tres funciones cumplidas en la Transición. Esta última dimensión esencial ahora y también entonces, aunque no estuviera tan reconocido como en nuestros días.

\section{Referencias bibliográficas}

AGUILERA, César (1989): El segundo frente. Revistas (literarias y estéticas), en Historia de comunicación en España. Ariel Comunicación, Barcelona.

ALTED, Alicia y AUBERT Paul (1995): Triunfo en su época. Editorial Casa de Velázquez, Madrid.

CANEL CRESPO, María José (2006): Comunicación política: una guía para su estudio y práctica. Editorial Tecnos, Madrid.

CANTAVELLA, Juan (2007): Manual de la entrevista periodística. Editorial Univérsitas, Madrid.

CASTRO TORRES, Carmen (2010): La prensa en la Transición española (19661978). Alianza Editorial, Madrid.

DÍAZ DORRONSORO, José María (2012): Cambio 16. Historia y testimonio de la mítica revista de la Transición democrática española, en el $40^{\circ}$ aniversario de su fundación. Editorial Saber y Comunicación, Madrid.

ESPINET, Francesc (1989): El segundo frente informativo: revistas y prensa especializada, en Historia de comunicación en España. Ariel Comunicación, Barcelona.

FRATTINI, Eric y QUESADA, Montse (1994): La entrevista. El arte y la ciencia. Editorial Eudema, Madrid.

GAITÁN MOYA, Juan Antonio (1992): La opinión de El País en la Transición española. Reis: Revista española de investigaciones sociológicas, número 57. Madrid, en http://dialnet.unirioja.es/servlet/articulo?codigo $=249775$

GARCÍA GONZÁLEZ, María Nieves (2006): La entrevista. Editorial Fragua, Madrid.

GARCÍA GONZÁLEZ, Gloria (2009): En la calle y en el papel, por la ruptura democrática. Triunfo, 1976-1977, en Prensa y democracia. Los medios de comunicación en la Transición. Biblioteca nueva, Madrid.

HALPERÍN, Jorge (1995): La entrevista periodística: intimidades de la conversación pública. Editorial Paidós, Barcelona.

MARTÍNEZ ALBERTOS, José Luis (1974): Redacción periodística. "Los estilos y los géneros en la prensa escrita”. ATE, Barcelona. 
MARTÍNEZ ALBERTOS, José Luis (2000): Curso General de redacción periodística: lenguaje, estilos y géneros periodísticos en prensa, radio, televisión y cine. Editorial Paraninfo Thomson Learning, Madrid.

MARTÍNEZ SOLER, José Antonio (2009): Cambio 16, doblón e historia internacional: conquistando la libertad palabra a palabra en Prensa y democracia. Los medios de comunicación en la Transición. Biblioteca nueva, Madrid.

MUÑOZ, Javier (1999). Prensa y franquismo. "Nuevo Diario": un ejemplo de la escasa apertura de la Ley Fraga. Revista Latina de Comunicación, número 20. La Laguna (Tenerife), en http://www.ull.es/publicaciones/latina/a1999eag/56nd.htm

OLMOS, Víctor (2002): Historia del ABC. 100 años clave en la historia de España. Editorial Plaza\&Janés, Barcelona.

PREGO, Victoria (1999): Diccionario de la Transición. Editorial Plaza\&Janés, Barcelona.

QUIROSA-CHEYROUZE Y MUÑOZ, Rafael (2009): Los medios de comunicación ante el proceso democratizador en España, en Prensa y democracia. Los medios de comunicación en la Transición. Biblioteca nueva, Madrid.

SUEIRO SEOANE, Susana (2009): El papel del diario El País en la Transición, en Prensa y democracia. Los medios de comunicación en la Transición. Biblioteca nueva, Madrid.

VAN NOORTWIJK, Annelies (2005). "Triunfo" y la reivindicación de la identidad cultural española dentro de la modernidad, 1962-1976. Historia del presente, número 5: 85-102.

\section{Marcos legales}

BOLETÍN OFICIAL DEL ESTADO. Ley 14/1966 de Prensa e Imprenta, del 18 de marzo de 1966. 19 de marzo de 1966, número 67, páginas 3310-3315

BOLETÍN OFICIAL DEL ESTADO. Real Decreto 24/1977 sobre libertad de expresión, del 1 de abril de 1977. 12 de abril de 1977, número 87, páginas 7928-7929

BOLETÍN OFICIAL DEL ESTADO. Constitución española de 1978, del 27 de diciembre de 1978. 29 de diciembre de 1978, número 311.1, páginas 29314-29339 